Journal of Engineering and Applied Sciences 14 (13): 4559-4563, 2019

ISSN: 1816-949X

(C) Medwell Journals, 2019

\title{
Crosswind Monitoring and Detection System at Highway with IoT Features
}

\author{
${ }^{1}$ Shahrizal Saat, ${ }^{1}$ Nur Shahirah Zakaria, ${ }^{2}$ Mohd Zaidi Mohd Tumari, ${ }^{3}$ Mohamed Saiful Firdaus Hussin, \\ ${ }^{1}$ Ahmad Nizamuddin Muhammad Mustafa and ${ }^{1}$ Mohd Anuar Adip \\ ${ }^{1}$ Department of Electronic and Computer Engineering Technology, \\ ${ }^{2}$ Department of Electrical Engineering Technology, \\ ${ }^{3}$ Department of Mechanical Engineering Technology, Faculty of Engineering Technology, \\ Universiti Teknikal Malaysia Melaka (UTeM), Durion Tunggal, Malaysia
}

\begin{abstract}
The term crosswinds are mean the horizontal winds blowing at $90^{\circ}$ from the direction of travels with the speed of $12.5 \mathrm{miles} / \mathrm{sec}$. Crosswind could make a trouble when traveling on wet or slippery roads, especially, during heavy rain and thunderstorms. It can make the vehicle overturning when crosswind blows through it. Windsock invisible at night can cause danger to highway users. This problem can increase the risk of being involved in the accident. To overcome this problem, the crosswind detection for direction and speed monitoring system at highway is being introduced. The signal from speed and direction sensor will be processed by controller and transmitted to the cloud. The outputs from the controller will be transmitted to the LCD screen to display the current information of crosswind and give the warning to the road users. LED light will indicate the status of the crosswind. Controller will update the data to the cloud through WiFi module. Data stored in the cloud can be accessed by user using Blynk App. It could help to reduce potential of accident occur, especially, at night for highway user.
\end{abstract}

Key words: Anemometer, wind direction sensor, crosswind, IoT, road users, current

\section{INTRODUCTION}

Malaysia has presented the North-South Expressway (PLUS) project across the country from the North-South. Then, the highways are introduced to shorten travel times and make it easier for users to repeat from anyplace. There is three crosswinds area, Senawang-Pedas/Linggi, on the North-South Expressway, Alor Gajah-Ayer Keroh on the North-South Expressway and the East Coast Expressway (Wahab and Kumar, 1998; Nawi, 2015). East Coast Expressway, ECE or (LPT) is also a highway in Malaysia gives connection from the West Coast of Peninsular Malaysia to the East Coast of Peninsular Malaysia. This highway through three states in the peninsula is Selangor, Pahang and Terengganu. It provides quicker alternatives to the old Kuala Lumpur-Kuantan Road FT2 and the Jerangau-Jabor FT14 Highway. Thus, it can decrease the travel time between different town and cities. There is a less awareness about the harmful crosswind in the community (Nasir et al., 2016; Dallina and Meor, 2014). They only put the notice board of crosswind area, the signboard of reducing the speed limit and used the conventional windsock as a manual crosswind indication as for the road user reference (Babu et al. 2014). This is important to produce a smart device which can help and alert the road users when the crosswind present ( $\mathrm{He}$ et al., 2015). This also can prevent an accident in the crosswind area on the highway.

The objective of the project is to develop a crosswind detector for direction and speed monitoring system by using Blynk App and to analyse the speed and direction of crosswind.

\section{MATERIALS AND METHODS}

Anemometer: The cup anemometer is consisting of three metal cups attached to the ends of horizontal arms mounted on a vertical shaft. The anemometer is a device used to measure wind speeds. The anemometer is designed to place outside and measure wind speed easily. This anemometer is used by connecting the black wire to power and ground signal, brown wire to 7-24VDC and measuring analog voltage on blue wire. The voltage will range from $0.4 \mathrm{~V}(0 \mathrm{~m} / \mathrm{sec}$ wind) up to $2.0 \mathrm{~V}$ (for wind

Corresponding Author: Shahrizal Saat, Department of Electronic and Computer Engineering Technology, Faculty of Engineering Technology, Universiti Teknikal Malaysia Melaka (UTeM), Durion Tunggal, Malaysia 


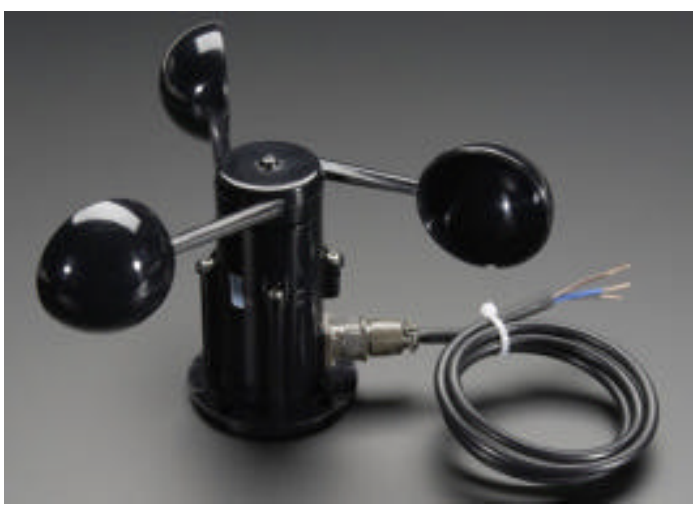

Fig. 1: Anemometer

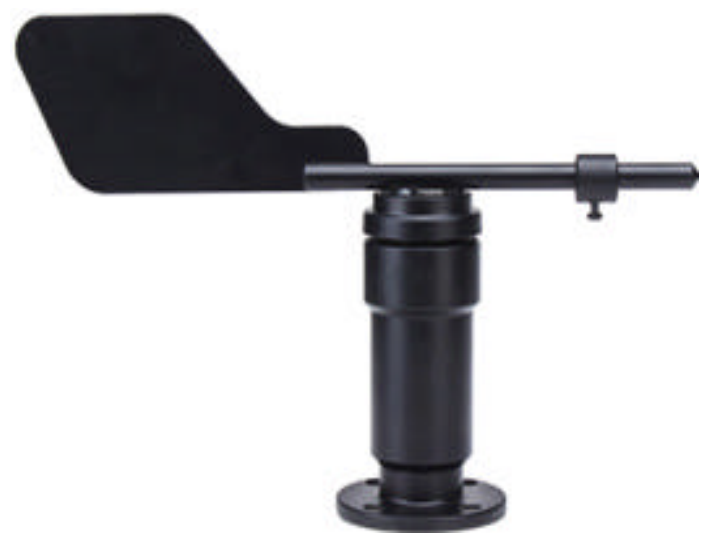

Fig. 2: Л-FS2 wind direction sensor

speed $32.4 \mathrm{~m} / \mathrm{sec}$ ). These sensors are rugged and easy to install. Moreover, this cable can be easily removed with some variants and has a weather connector. Figure 1 shows the anemometer.

JL-FS2 wind direction sensor: Aluminum alloy wind direction sensor uses a special mold die casting process, high dimension tolerance of very small surface accuracy. The internal circuits through protective treatment, sensors have high strength, weather resistance, anti-corrosion and water resistance. Then, cable connectors for military plug have good anti-corrosion, anti-rust performance to ensure long-term use of the instrument and connect with internal import bearing system to ensure speed acquisition accuracy. Figure 2 shows the JL-FS2 wind direction sensor.

ESP8266 WiFi module: The ESP8266 WiFi module is an independent SOC with integrated TCP/IP protocol stack that can give any microcontroller access to $\mathrm{WiFi}$ network. Besides, ESP8266 WiFi module is cheaper than Bluetooth module. By using the ESP8266, users can

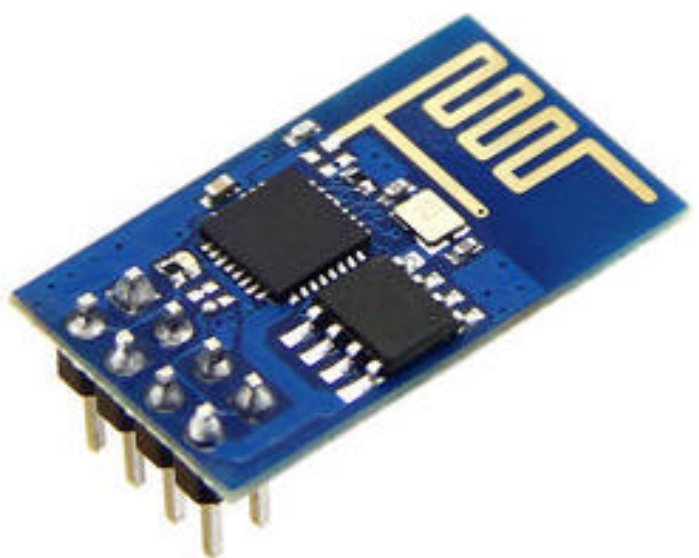

Fig. 3: ESP8266 WiFi module

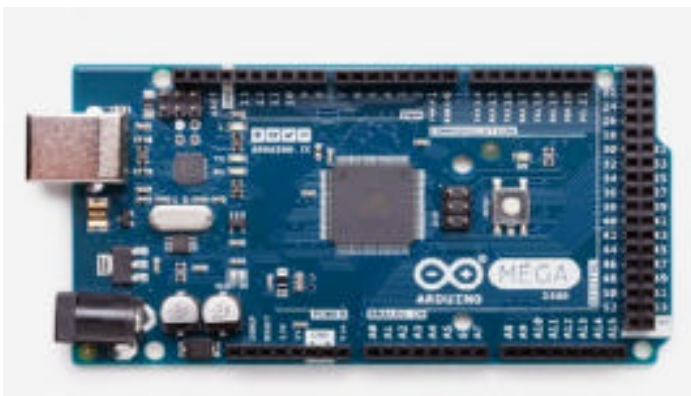

Fig. 4: Arduino Mega 2560

connect the module to the internet and use it easily. Then, this module has a powerful processing and storage capability in the board that allows it to be integrated with the sensors and other application specific devices through its GPIOs with minimal development up-front and minimal loading during runtime. Small size and low cost makes it ideal for sensor nodes. It works on $3.3 \mathrm{~V}$ and uses current up to $250 \mathrm{~mA}$. Figure 3 shows the ESP8266 WiFi module.

Arduino Mega 2560: The Arduino Mega refer to the microcontroller board based on the ATmega 2560. It consists of 54 digital input/output pins (of which 15 can be used as PWM outputs), 16 analog inputs, 4 UARTs (hardware serial ports), a $16 \mathrm{MHz}$ crystal oscillator, a USB connection, a power jack, an ICSP header and a reset button. Moreover, it has everything needed to support the microcontroller; simply connect it to a computer with a USB cable or power it with an AC-DC adapter or battery to get started (Fig. 4).

Block diagram of crosswind detection monitoring system: The signal from speed and direction sensor will be processed by Arduino and transmitted to the Blynk 


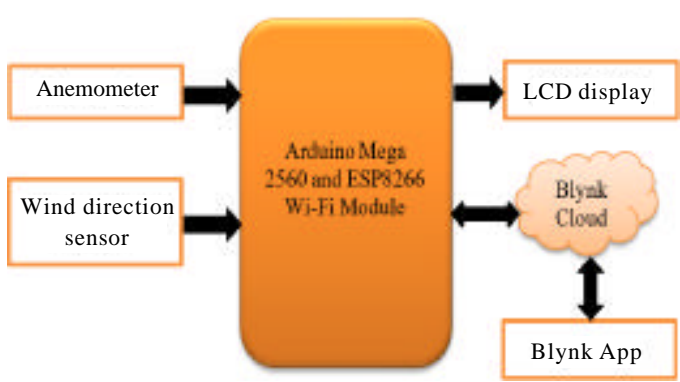

Fig. 5: Block diagram of crosswind detection monitoring system

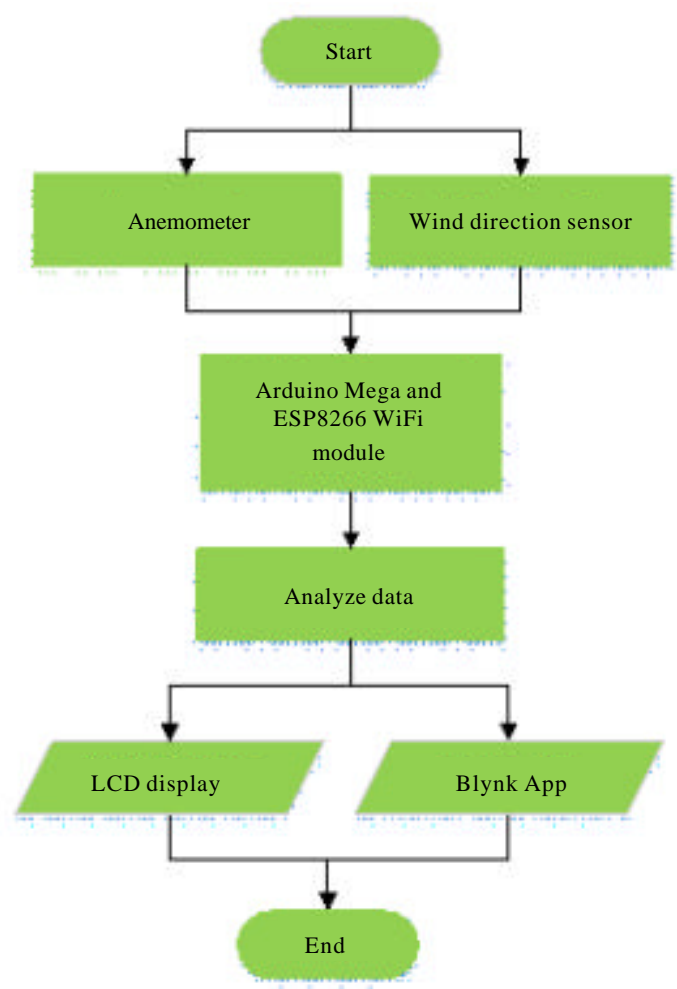

Fig. 6: Flowchart project function

cloud. The outputs from the Arduino will be transmitted to the LCD screen to display the current information of crosswind and give the warning to the road users. LED light will indicate the status of the crosswind. Then, Arduino will update the data to the Blynk cloud through WiFi module. Data stored in the Blynk cloud will be accessed by Blynk app. Road users can get information of wind conditions using the Blynk App (Fig. 5).

Flowchart project function: Figure 6 and 7 shows the flowchart project function.

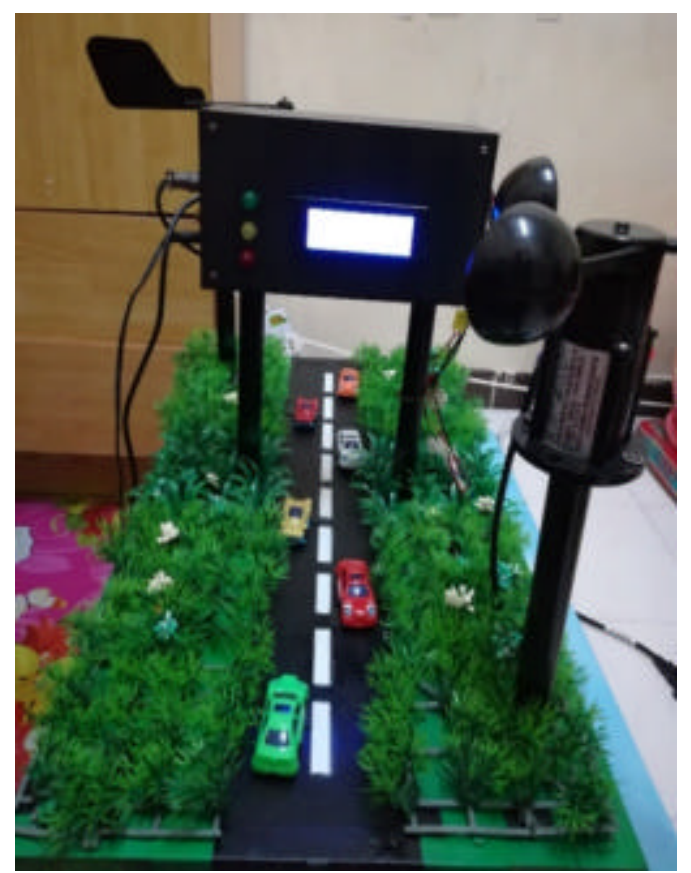

Fig. 7: Prototype of project

\section{RESULTS AND DISCUSSION}

Relationship between time response with wind direction: The data were taken 5 times to get an average time response. Based on the observation, the time response was taken when the wind direction is changed between $0-45^{\circ}, 0-90^{\circ}, 0-135^{\circ}, 0-180^{\circ}, 0-225^{\circ}$, $0-270^{\circ}, 0-315^{\circ}$ and $0-360^{\circ}$. Based on the results obtained, when the wind direction far from $0^{\circ}$, the longer the time response is taken. This is because the time response is influenced by the change of the wind direction. Figure 8 shows graph for time response against direction.

Relationship between output voltage with wind direction: Table 1 shows the relationship between output voltage with wind direction. The output voltage increases proportionally to the degree value. Then, based on the graph in Fig. 9, the output voltage increase linearly with the wind direction.

Relationship between time response with wind speed: The data is taken by using different speed of wind which is started from scale $0-1,0-2$ and $0-3$. Wind scale given by using portable table fan. According to the results, when wind speed increased, the time response is decreased. Figure 10 shows the graph of time response against table fan speed. 


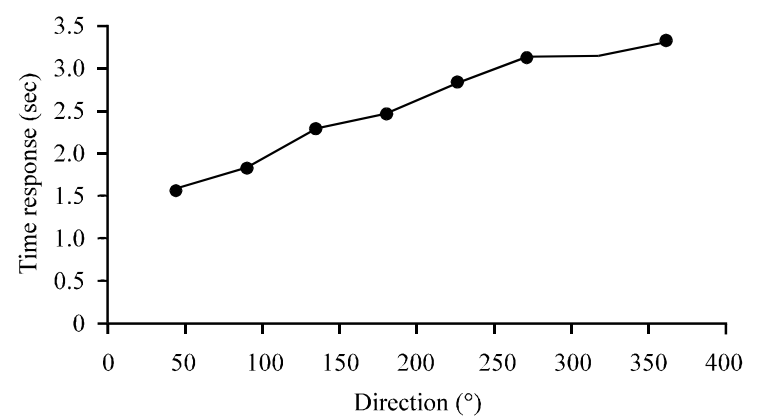

Fig. 8: Graph for time response against direction

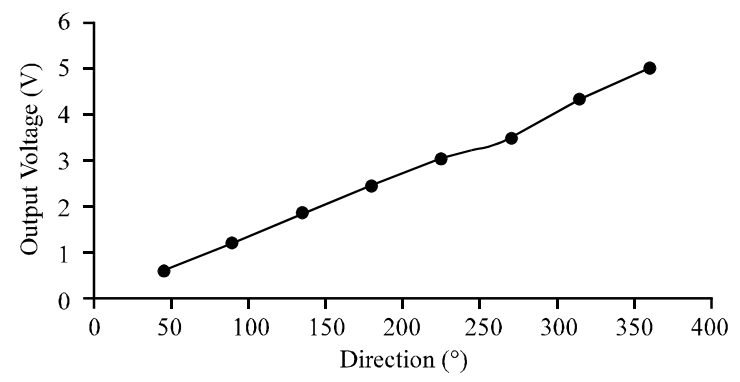

Fig. 9: Graph for output voltage against wind direction

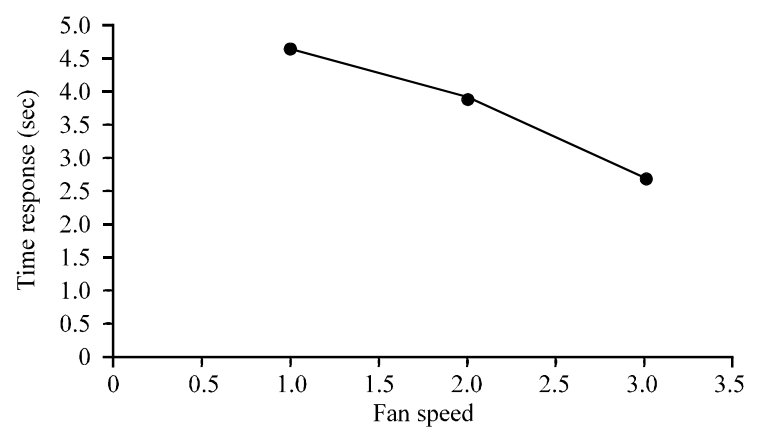

Fig. 10: Graph for time response against fan speed

Table 1: Output voltage with wind direction relationship

\begin{tabular}{lc}
\hline Direction $\left(^{\circ}\right)$ & Output Voltage $(\mathrm{V})$ \\
\hline 45 & 0.59 \\
90 & 1.22 \\
135 & 1.85 \\
180 & 2.46 \\
225 & 3.04 \\
270 & 3.47 \\
315 & 4.34 \\
360 & 5.00 \\
\hline
\end{tabular}

Table 2: Relationship between output voltage with wind speed

\begin{tabular}{lcc}
\hline Scale speed & Wind speed $(\mathrm{km} / \mathrm{h})$ & Output Voltage $(\mathrm{V})$ \\
\hline 1 & 6.84 & 0.29 \\
2 & 13.00 & 0.56 \\
3 & 21.09 & 0.90 \\
\hline
\end{tabular}

Relationship between output voltage with wind speed: Table 2 shows the relationship between the output voltage with wind speed. The output voltage increases

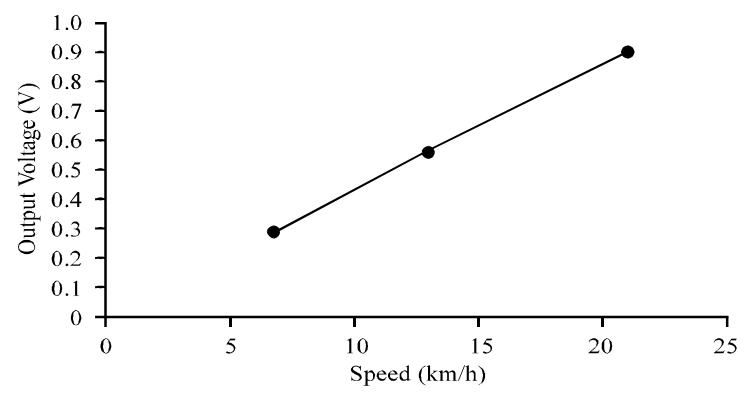

Fig. 11: Graph for output voltage against wind speed

proportionally to the wind speed. Then, the graph obtained in the figure indicated the relationship between the voltage and wind speed is linear (Fig. 11).

\section{CONCLUSION}

As a conclusion, this project is very useful as it will enable the road users to be aware on danger of crosswind. This project is expected to reduce an accident among the road users at crosswind area. The objectives of the project has been successfully achieved. It is able to develop a crosswind detector for direction and speed monitoring system by using Android application. In this project, Blynk App is used to create the application for Android. Blynk App is one of the software that can be used to create the application for Android. Furthermore, Blynk App is a digital dashboard where the users can build a graphic interface for projects by simply dragging and dropping widgets. Blynk is designed for Internet of Things (IoT) and it can control hardware remotely, it can display sensor data, stored data, visualize it and else. This software is easier to use have many features and also no additional hardware needed to use it. Users can easily get the current information about the crosswind either via. smartphone or local indication on the highway.

\section{ACKNOWLEDGEMENT}

The researchers would like to thank for the support given to this research by Ministry of Higher Education Malaysia and Universiti Teknikal Malaysia Melaka(UTeM)underRAGS/1/2015/TK0/FTK/03/B00111 research grant.

\section{REFERENCES}

Babu, S.D., A.S. Acharjya and S. Alam, 2014. Design and construction of microcontroller based wind speed and direction monitoring system. Proceedings of the 2014 9th International Forum on Strategic Technology (IFOST), October 21-23, 2014, IEEE, Cox's Bazar, Bangladesh, ISBN:978-1-4799-6060-6, pp: 284-288. 
Dallina, W.N.F. and M.N. Meor, 2014. Wind speed sensor for highway users. MSc Thesis, UniKL Malaysian Institute of Information Technology, Kuala Lumpur, Malaysia.

He, Y., X. Yan, D. Chu, C. Wu and Z. Chen, 2015. Contribution of wind forces to rollover stability of heavy duty vehicle. Proceedings of the 2015 International Conference on Transportation Information and Safety (ICTIS), June 25-28, 2015, IEEE, Wuhan, China, ISBN:978-1-4799-8693-4, pp: 173-176.
Nasir, H.M., W.N.F. Dallina, S. Marzukhi and Z. Zainol, 2016. Wind speed detection system: Framework and implementation. Proceedings of the 2016 International Conference on Information and Communication Technology (ICICTM), May 16-17, 2016, IEEE, Kuala Lumpur, Malaysia, ISBN:978-1-5090-0413-3, pp: 61-64.

Nawi, A.A.M., 2015. Design and development of low cost crosswind indicator. MSc Thesis, University Technology Malaysia, Skudai, Johor, Malaysia.

Wahab, A.A. and H.M. Kamar, 1998. [Late wind properties at $212 \mathrm{~km}$ plus case study highway (In Malay)]. J. Technol., 29: 71-79. 